Original Research

\title{
Studi Toksisitas Akut dari Herbisida Senyawa Aktif Parakuat, Glifosat, dan Metsulfuron pada Cacing Tanah (Eisenia fetida)
}

\author{
Pajar Huzaifah ${ }^{1}$, Ramadhani Eka Putra ${ }^{2}{ }^{*}$, Ida Kinasih ${ }^{3}$ \\ ${ }^{1}$ Jurusan Biologi, Sekolah Ilmu dan Teknologi Hayati, Insitut Teknologi Bandung, Bandung-Indonesia \\ 2 Jurusan Rekayasa Pertanian, Sekolah Ilmu dan Teknologi Hayati, Institut Teknologi Bandung, Bandung- \\ Indonesia \\ ${ }^{3}$ Jurusan Biologi, Universitas Islam Negeri Sunan Gunung Djati, Bandung-Indonesia \\ * corresponding author: ramadhani@sith.itb.ac.id
}

\begin{abstract}
Earthworm plays important role in the terrestrial ecosystem as decomposer and sensitive to environmental changes. Herbicide application as an effort to improve farm productivity may produce some effects on earthworms. The objective of this study was to find the toxicity level of paraquat, glyphosate, and metsulfuron, the three most common active ingredients of herbicide, on earthworm, Eisenia fetida. Three hundred adult earthworms, weighed between 300 to $600 \mathrm{mg}$, were divided evenly into one control group and four treatment groups for each herbicide. A dose of $0,500,1000,2000,4000 \mathrm{mg} / \mathrm{kg}$ for paraquat; 0 , 2500, 5000, 10000, $20000 \mathrm{mg} / \mathrm{kg}$ for glyphosate; and 0, 750, 1500, 3000, $6000 \mathrm{mg} / \mathrm{kg}$ for metsulfuron was sprayed and mixed evenly on medium of earthworms medium. Each treatment was replicated 4 times. The mortality rate was recorded daily for 14 days and used as data to calculated $L C_{50}$ of each herbicide. $L C_{50}$ of paraquat, glyphosate, and metsulfuron was $951.93 \pm 115.63$ $\mathrm{mg} / \mathrm{kg}, 5456.36 \pm 514.62 \mathrm{mg} / \mathrm{kg}$, and $2599.96 \pm 211.85 \mathrm{mg} / \mathrm{kg}$, respectively. On the other hand, the weight of earthworm has a negative correlation with the dose of herbicide applied to the medium. Based on this study, paraquat was the most toxic herbicide followed by metsulfuron and glyphosate.
\end{abstract}

Keywords: eisenia fetida, glyphosate, LC50, metsulfuron, paraquat, toxicity

\begin{abstract}
Abstrak- Cacing tanah memiliki peran yang penting di ekosistem terestrial sebagai dekomposer dan peka terhadap pengaruh lingkungan. Penggunaan herbisida sebagai sarana peningkatan produksi lahan pertanian kemungkinan memiliki dampak terhadap cacing tanah. Penelitian ini bertujuan untuk menentukan $\mathrm{LC}_{50}$ (15 hari) dari herbisida kelompok parakuat, glifosat, dan metsulfuron pada Eisenia fetida dan pengaruhnya terhadap perubahan berat cacing tanah. Pada penelitian ini digunakan tiga ratus cacing tanah dewasa (sudah terbentuk klitelum) dengan berat masing-masing antara 300-600 mg yang dibagi menjadi satu kelompok kontrol dan 4 kelompok perlakuan untuk tiap kelompok jenis herbisida. Herbisida didedahkan ke dalam media tempat tinggal cacing sebanyak 0, 500, 1000, 2000, $4000 \mathrm{mg} / \mathrm{kg}$ untuk parakuat; 0, 2500, 5000, 10000, $20000 \mathrm{mg} / \mathrm{kg}$ untuk glifosat; dan 0, $750,1500,3000,6000 \mathrm{mg} / \mathrm{kg}$ untuk metsulfuron. Masing-masing perlakuan dilakukan empat kali pengulangan. Jumlah cacing tanah yang mati dicatat selama 14 hari pengamatan dan pada akhir pengamatan ditentukan nilai $\mathrm{LC}_{50}$ dari setiap herbisida. Nilai $\mathrm{LC}_{50}$ yang didapat pada kelompok parakuat, glifosat, dan metsulfuron adalah sebesar $951.93 \pm 115.63 \mathrm{mg} / \mathrm{kg}, 5456.36 \pm 514.62$ $\mathrm{mg} / \mathrm{kg}$, dan $2599.96 \pm 211.85 \mathrm{mg} / \mathrm{kg}$. Berat cacing tanah didapatkan menurun seiringan dengan meningkatnya konsentrasi herbisida. Dengan demikian, dapat disimpulkan bahwa herbisida dari kelompok senyawa aktif parakuat memiliki toksisitas paling tinggi, disusul oleh herbisida dari kelompok senyawa aktif metsulfuron dan glifosat.
\end{abstract}

Kata kunci: eisenia fetida, glifosat, LC50, metsulfuron, parakuat, toksisitas

\section{PENDAHULUAN}

Seiring dengan peningkatan populasi manusia, maka pertanian dituntut untuk dapat menghasilkan produk lebih banyak. Salah satu tantangan dalam sistem produksi pertanian adalah peningkatan produksi ini harus dilakukan dengan tingkat peningkatan luas area tanam dalam jumlah rendah (pada 50 tahun terakhir luas area tanam hanya bertambah 10\%) (Tilman, Cassman, Matson, Naylor \& Polasky 2002). Kondisi ini menyebabkan aplikasi dari proses intensifikasi produksi dengan penambahan energi dari luar sistem salah satunya melalui aplikasi pestisida. Salah satu jenis pestisida yang umum diaplikasikan adalah herbisida dengan jenis herbisida berbasis glifosat sebagai jenis yang paling umum diaplikasikan bila dibandingkan herbisida jenis lain (berbasis parakuat dan metsulfuron) (Woodburn 2000). Secara teoritis, herbisida mengandung senyawa aktif yang efektif bekerja pada jalur metabolism tertentu pada tumbuhan sehingga aman bagi lingkungan. Akan tetapi, terdapat 
laporan dari efek merugikan bagi organisme non target seperti amfibi (Relyea 2005), jamur mikoriza (Zaller, Heigl, Ruess, Grabmaier 2014), dan cacing tanah (Pelosi, Toutous, Chiron, Dubs, Hedde, Muratet, Ponge, Salmon \& Makowski 2013; Gaupp-Berghausen, Hofer, Rewald \& Zaller 2015).

Cacing tanah merupakan hewan yang sering menjadi penyusun utama dari biomasa hewan pada tanah dan memiliki peran penting sebagai dekomposer dan sifatnya yang peka akibat pengaruh lingkungan (Edwards \& Bohlen 1996; Haimi 2000). Cacing tanah merupakan salah satu dari perekayasa ekosistem yang dapat merubah kondisi habitat mereka melalui serangkaian aktivitas yang dilakukan terutama aktivitas makan (Jones, Lawton \& Shachak 1994). Aktivitas makan yang dilakukan dengan melibatkan proses penghancuran serasah, mineralisasi, dan produksi kotoran berperan besar dalam meningkatkan keberadaan nutrisi tanah sehingga meningkatkan produktivitas tanaman (Scheu 2003; van Groenigen, Lubbers, Vos, Brown, De Deyn \& van Groenigen 2014). Dengan peran penting mereka pada ekosistem tanah, maka setiap aplikasi senyawa kimia yang memberikan efek negatif pada populasi cacing tanah (Paoletti \& Bressan 1996; Sari, Niswati, Arif, \& Yusnaini 2015) dapat memberikan efek langsung maupun tidak langsung fungsi ekosistem terkait dengan pertumbuhan tanaman (Blouin, Hodson, Delgado, Baker, Brussaard, Butt, Dai, Dendooven, Peres, Tondoh, Cluzeau \& Brun 2013).

Jenis cacing tanah yang paling umum digunakan sebagai spesies model menentukan dampak ekologis dari logam berat dan senyawa kimia lain yang mengontaminasi tanah adalah Eisenia fetida (Verrell \& Van Buskrik 2004; Yasmin \& D'Souza 2007; Correira \& Moreira 2010; Zhou, Wang, Li, Sun, Yu \& Zhou 2013). Penelitian telah melaporkan efek dari senyawa aktif pestisida pada E. fetidia (De Silva, Pathiratne \& van Gestel 2009). Akan tetapi, sebagian besar penelitian melakukan pengujian efek toksisitas hanya pada satu jenis senyawa aktif saja sehingga terdapat kekurangan dalam pengetahuan terkait efek dari aplikasi beberapa jenis senyawa aktif terhadap kondisi fisiologi cacing tanah. Hal ini menjadi tujuan dari penelitian ini dan pengetahuan ini akan memberikan dasar penting dalam aplikasi bagi dunia pertanian, restorasi lingkungan, dan konservasi lingkungan.

\section{METODE}

\section{Persiapan Penelitian}

Pada penelitian ini digunakan cacing tanah yang berasal dari spesies $E$. fetida. Kultur cacing tanah diperoleh dari kelompok budi daya cacing tanah di Bandung. Cacing tanah yang digunakan adalah cacing tanah yang sudah dewasa (telah terbentuk klitelum) dengan berat antara 300 - $600 \mathrm{mg}$ per ekor. Cacing tanah diaklimatisasi selama satu minggu sebelum pengujian di dalam media yang terdiri dari campuran kotoran kuda dan cacahan kawung (1:1), ditempatkan di dalam baki plastik dan diletakkan di Laboratorium Toksikologi, SITH, ITB. Cacing diberi pakan berupa ampas tahu setiap harinya dan disimpan di dalam suhu ruangan.

\section{Uji Toksisitas}

Toksisitas senyawa uji ditentukan dengan nilai $\mathrm{LC}_{50}$. Penentuan $\mathrm{LC}_{50}$ yang dilakukan pada penelitian ini menggunakan herbisida yang berasal dari kelompok bahan aktif glifosat (Roundup ${ }^{\circledR} 486 \mathrm{SL}$ ), parakuat (Noxone ${ }^{\circledR} 297 \mathrm{SL}$ ), dan metsulfuron (Metsulindo ${ }^{\circledR} 20 \mathrm{WP}$ ). Metode yang dilakukan untuk uji toksisitas LC50 terhadap cacing tanah merujuk pada OECD Guideline for Testing of Chemicals No. 207 "Earthworm, Acute Toxicity Tests" yang disertai dengan beberapa modifikasi (OECD 1984). Pada pengujian tiap bahan aktif, masing-masing digunakan empat kelompok perlakuan herbisida dengan konsentrasi beragam dan satu kelompok kontrol. Tiap kelompok perlakuan terdiri dari 4 pengulangan untuk setiap kelompok. Sebanyak 200 gram media campuran kotoran kuda dan cacahan kawung (1:1) yang sudah dicampurkan dengan herbisida dengan konsentrasi yang akan diuji, dimasukkan ke dalam wadah plastik kemudian 15 ekor cacing tanah ditempatkan di media uji tersebut dengan cara diletakkan di atas permukaan media. Herbisida dicampurkan ke dalam media dengan cara 
Pajar, H., et al., Studi Toksisitas Akut dari Herbisida Senyawa Aktif Parakuat, Glifosat, dan Metsulfuron pada Cacing Tanah (Eisenia fetida), KELUWIH: Jurnal Sains dan Teknologi, Vol.2(2), 64-69, Agustus 2021.

https://doi.org/10.24123/saintek.v2i2.3998

disemprotkan kemudian diaduk merata. Kelembaban media perlakuan dijaga mencapai rentang $60-70 \%$ dengan cara penyemprotan dengan akua deion.

\section{Konsentrasi Uji}

Konsentrasi uji yang dilakukan untuk kelompok herbisida dari bahan aktif glifosat antara lain 0, 2500, 5000, 10000, dan $20000 \mathrm{mg} / \mathrm{kg}$; untuk kelompok herbisida dari bahan aktif parakuat antara lain 0, 500, 1000, 2000, dan $4000 \mathrm{mg} / \mathrm{kg}$; sedangkan untuk kelompok herbisida dari bahan aktif metsulfuron antara lain 0, 750, 1500, 3000, dan $6000 \mathrm{mg} / \mathrm{kg}$.

\section{Pengumpulan dan Analisis Data}

Pengumpulan data untuk penentuan $\mathrm{LC}_{50}$ bagi glifosat, parakuat, dan metsulfuron terhadap E. fetida masing-masing dilakukan pada hari ke-14 setelah pendedahan. Berat cacing tanah hidup dihitung pada awal dan akhir perlakuan.

Analisis $\mathrm{LC}_{50}$ dilakukan berdasarkan metode probit dengan analisis grafik menggunakan program StatPlus ${ }^{\circledR} 2009$ Professional sedangkan analisis perbedaan berat cacing tanah dari tiap kelompok perlakuan dilakukan menggunakan metode One-way ANOVA, IBM SPSS $^{\circledR}$ Statistics pada tingkat signifikansi $95 \%$ diikuti dengan LSD post-hoc test.

\section{HASIL DAN BAHASAN}

\section{Penentuan LC $_{50}$ Parakuat, Glifosat, dan Metsulfuron}

Hasil pengamatan dan analisis data dengan Metode Probit menunjukkan bahwa nilai $\mathrm{LC}_{50}$ senyawa aktif parakuat pada $E$. fetida (tingkat kepercayaan 95\%) adalah sebesar $951.93 \pm$ $115.63 \mathrm{mg} / \mathrm{kg}$ (Gambar 1) sedangkan untuk senyawa aktif glifosat sebesar $5456.36 \pm 514.62$ $\mathrm{mg} / \mathrm{kg}$ (Gambar 2) dan untuk metsulfuron sebesar $2599.96 \pm 211.85 \mathrm{mg} / \mathrm{kg}$ (Gambar 1).
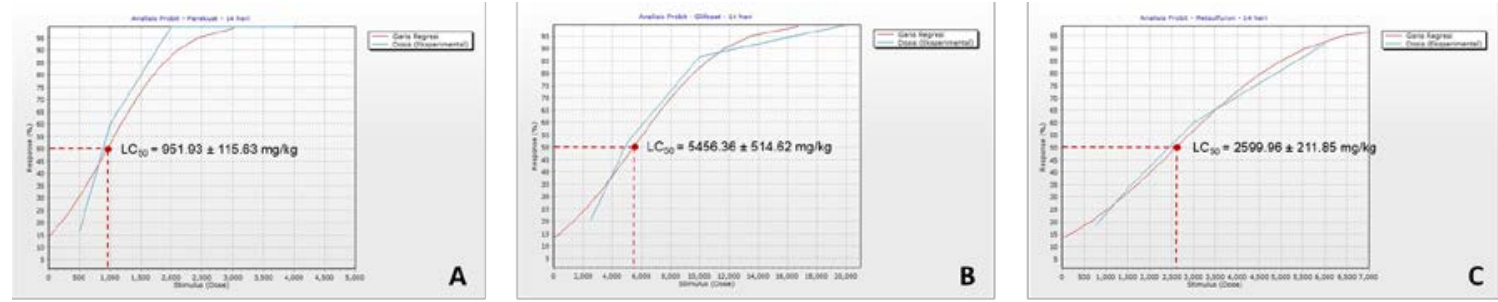

Gambar 1. $\mathrm{LC}_{50}$ (A) parakuat, (B) glifosat, dan (c) metsulfuron pada E. fetida.

Pada analisis probit, nilai slope menunjukkan keragaman suatu dosis terhadap respons. Semakin tinggi nilai slope maka dibutuhkan sedikit pertambahan dari konsentrasi dosis untuk menghasilkan respons yang lebih tinggi (Hong, Meier \& Deininger 1988). Dari analisis probit kali ini, didapat nilai slope yang paling tinggi dari ketiga jenis senyawa aktif herbisida yaitu berasal dari kelompok parakuat sehingga menunjukkan bahwa parakuat bersifat paling toksik di antara ketiga jenis senyawa aktif lain, disusul oleh metsulfuron kemudian glifosat (Tabel 1).

\section{Tabel 1}

Nilai $L_{50}$, Persamaan Regresi, dan nilai Slope dari Toksisitas dari Parakuat, Glifosat, dan Metsulfuron terhadap E. Fetida

\begin{tabular}{cccc}
\hline Herbisida & $\mathbf{L C}_{50}(\mathbf{m g} / \mathbf{k g})$ & Persamaan Regresi & Slope \\
\hline Parakuat & $951.93 \pm 115.63$ & $\mathrm{Y}=0.0253 \mathrm{X}+17.33$ & 0.0253 \\
Glifosat & $5456.36 \pm 514.62$ & $\mathrm{Y}=0.0049 \mathrm{X}+14.54$ & 0.0049 \\
Metsulfuron & $2599.96 \pm 211.85$ & $\mathrm{Y}=0.0154 \mathrm{X}+9.73$ & 0.0154 \\
\hline
\end{tabular}


Hasil penelitian ini menunjukkan bahwa parakuat merupakan senyawa aktif yang memiliki sifat toksik tertinggi dibandingkan senyawa lainnya. Hasil ini mendukung beberapa laporan terdahulu yang menunjukkan toksisitas parakuat yang relatif lebih tinggi pada cacing tanah bila dibandingkan dengan senyawa aktif herbisida lain seperti glifosat dan terutama metsulfuron yang dilaporkan sebagai senyawa yang tidak memiliki efek racun pada cacing tanah (Muangphra, Kwankua \& Gooneratne 2014; Lewis, Tzilivakis, Warner \& Green 2016). Tingkat racun yang tinggi dari parakuat terhadap cacing tanah karena sifat dari senyawa aktif parakuat yang dapat menyebabkan kerusakan pada DNA (genotoxic) secara signifikan (Muangphra, Kwankua \& Gooneratne 2014). Kerusakan pada DNA dapat mengganggu proses enzimatis dan yang sangat penting bagi kehidupan cacing tanah.

Bila dibandingkan dengan penelitian lain, nilai toksisitas pada seluruh senyawa uji jauh lebih rendah (Muangphra, Kwankua \& Gooneratne 2014; de Santo, Guerra, Vianna, Torres, Marchioro, Niemeyer 2019). Nilai toksisitas yang lebih rendah ini dapat disebabkan karena proses inaktivasi yang relatif lebih cepat terutama pada parakuat dan glifosat. Bersama dengan parakuat, glifosat merupakan senyawa yang mengalami proses inaktivasi pada tanah (Hawkes 2014) yang menjadikan mereka sebagai herbisida favorit karena tanah dapat langsung ditanami oleh tanaman utama (Bromilow 2004). Proses inaktivasi dapat terjadi karena pengikatan senyawa pada materi organik (Sartori \& Vidrio 2018), faktor fisik dan kimia (Piola, Fuchs, Oneto, Basack, Kesten \& Casabe 2013) atau aktivitas dari mikroorganisme (Walker, Cotterill, Welch 1989; Parte, Mohekar \& Kharat 2017) dimana sangat ditentukan oleh media tempat cacing hidup. Pada penelitian ini digunakan media dalam bentuk kotoran kuda yang mengandung materi organik dan mikroorganisme tinggi yang kemungkinan berperan besar dalam mempercepat proses inaktivasi dari senyawa herbisida.

\section{Perubahan Berat Cacing Tanah}

Hasil studi menunjukkan bahwa terjadi penurunan berat badan cacing yang signifikan seiring dengan peningkatan dosis dari parakuat dan metsulfuron sehingga mencapai nilai stagnan pada dosis $1000 \mathrm{mg} / \mathrm{kg}$ sedangkan glifosat pada dosis $10.000 \mathrm{mg} / \mathrm{kg}$ (Gambar 2).
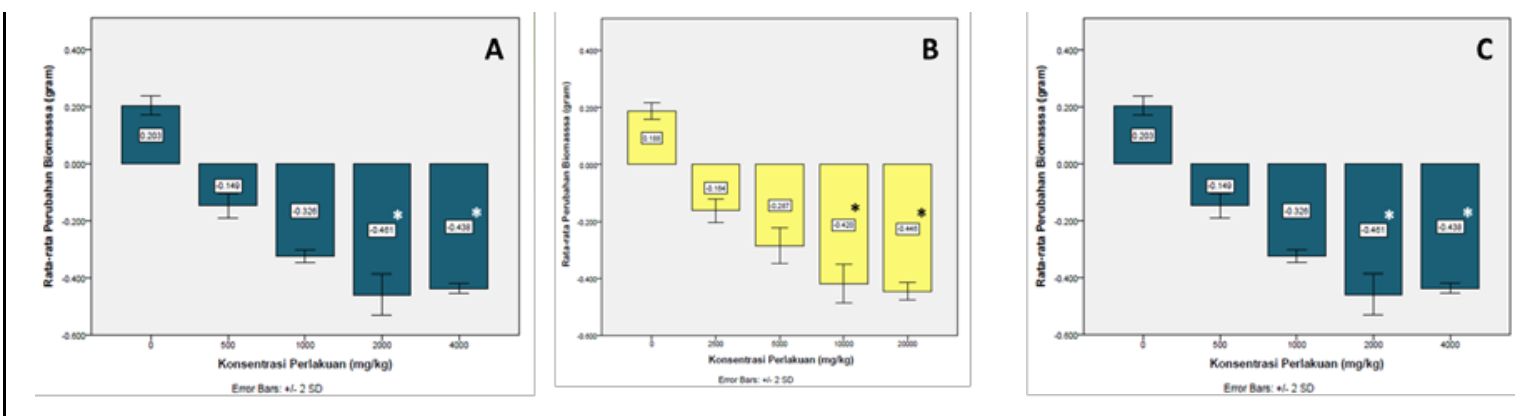

Gambar 2. Perubahan rata-rata berat E. fetida pada perlakuan (A) parakuat, (B) glifosat, dan (C) metsulfuron (* tingkat penuruan tertinggi dan tidak berbeda nyata).

Penurunan berat badan cacing tanah pada penelitian ini sesuai dengan beberapa penelitian terdahulu yang melaporkan efek negatif dari herbisida pada berat dari cacing tanah (Yasmin \& D'Souza 2009; Correira \& Moreira 2010; Santadino, Coviella \& Momo 2014; Pochron, Simon, Mirza, Littleton, Sahebzada \& Yudell 2020) terutama pada tahap juvenile (Dominguez, Brown, Sautter, de Oliveira, de Vasconcelos, Niva, Bartz \& Bedano 2016). 
Mekanisme yang bekerja terkait dengan penurunan berat tubuh merupakan hal yang dapat menjadi dasar dari riset lanjutan.

\section{SIMPULAN}

Berdasarkan hasil studi toksisitas akut terhadap cacing tanah, didapat nilai LC $_{50} E$. fetida akibat herbisida senyawa aktif parakuat, metsulfuron, dan glifosat, secara berurutan adalah $951.93 \pm 115.63 \mathrm{mg} / \mathrm{kg}, 5456.36 \pm 514.62 \mathrm{mg} / \mathrm{kg}$, dan $2599.96 \pm 211.85 \mathrm{mg} / \mathrm{kg}$. Ketiga jenis herbisida juga mengakibatkan penurunan yang signifkan terhadap berat cacing tanah dan mencapai nilai stagnan pada level toksisitas tinggi.

\section{UCAPAN TERIMA KASIH}

Penelitian ini sebagian dibiayai oleh program penelitian Riset ITB 2014 yang diperoleh oleh penulis korespodensi.

\section{PUSTAKA ACUAN}

Blouin M, Hodson ME, Delgado EA, Baker G, Brussaard L, Butt KR, Dai J, Dendooven L, Peres G, Tondoh JE, Cluzeau D \& Brun JJ 2013, 'A review of earthworm impact on soil function and ecosystem services', European Journal of Soil Science, 64(2), 161-182.

Correira FV \& Moreira J 2010, 'Effects of Glyphosate and 2,4-D on Earthworms (Eisenia foetida) in laboratory tests, Bulletin of Environmental Contamination and Toxicology, 85(3), 264268.

De Santo FB, Guerra N, Vianna MS, Torres JPM, Marchioro CA, Niemeyer JC 2019, 'Laboratory and field test for risk assessment of metsulfuron-methyl-based herbicides for soil fauna', Chemosphere, 222, 645-655.

De Silva PMCS, Pathiratne A \& van Gestel CAM 2009, 'Influence of temperature and soil type on the toxicity of three pesticide to Eisenia andrei', Chemosphere, 76(10), 1410-1415.

Dhadich, SM, Dhadich, H \& Verma, RC 2008, 'Comparative study on storage of fruits and vegetables in evaporative cool chamber an in ambient', Internasional Journal of Food Engineering, 2, 1-11.

Dominguez A, Brown GG, Sautter KD, de Oliveira CMR, de Vasconcelos EC, Niva CC, Bartz MLC \& Bedano JC 2016, 'Toxicity of AMPA to the earthworm Eisenia andrei Bouche, 1972 in tropical artificial soil. Scientific Reports, 6, 19731.

Edwards CA \& Bohlen PJ 1996, 'Biology and Ecology of Earthworms', London : Chapman and Hall.

Gaupp-Berghausen M, Hofer M, Rewald B \& Zaller JG 2015,' Glyphosate-based herbicides reduce the activity and reproduction of earthworms and lead to increased soil nutrient concentrations', Scientific Reports, 5, 12886.

Haimi J 2000, 'Decomposer Animals and Bioremediation of Soils', Environmental Pollution, 107, 233-238.

Hong WH, Meier PG \& Deininger RA 1988, 'Estimation of a single probit line from multiple toxicity test data,' Aquatic Toxicology, 12, 193-202.

Jones CG, Lawton JH \& Shachak M 1994, 'Organisms as ecosystem engineers', Oikos, 69, 373386.

Lewis KA, Tzilivakis J, Warner D \& Green A 2016, 'An international database for pesticide risk assessment and management', Human and Ecological Risk Assessment, 22, 1050-1064.

Muangphra P, Kwankua W \& Gooneratne R 2014, 'Genotoxic effects of glyphosate or paraquat on earthworm coelomocytes', Environmental Toxicology, 29(6), 612-620.

OECD 1984, 'Earthworm Acute Toxicity Tests - OECD Guideline for Testing of Chemicals' http://www.oecd.org/chemicalsafety/risk-assessment/1948293.pdf. (18 Februari 2014).

Paoletti MG \& Bressan M 1996, 'Soil invertebrates as bioindicators of human disturbance', Critical Reviews in Plant Sciences, 15(1), 21-62. 
Parte SG, Mohekar AD \& Kharat AS 2017, 'Microbial degradation of pesticide: a review', African Journal of Microbiology Research, 11, 992-1012.

Pelosi C, Toutous L, Chiron F, Dubs F, Hedde M, Muratet A, Ponge JF, Salmon S \& Makowski D 2013 , 'Reduction of pesticide use can increase earthworm populations in wheat crops in a European temperate region', Agriculture, Ecosystem \& Environment, 181, 223-230.

Piola L, Fuchs J, Oneto ML, Basack S, Kesten E \& Casabe N 2013, 'Comparative toxicity of two glyphosate-based formulation to Eisenia andrei under laboratory conditions', Chemosphere, 91, 545-551.

Pochron S, Simon L, Mirza A, Littleton A, Sahebzada F \& Yudell M 2020, 'Glyphosate but not Roundup ${ }^{\circledR}$ harms earthworms (Eisenia fetida)', Chemosphere, 241, 125017.

Relyea RA 2005, 'The lethal impacts of Roundup and predatory stress on six species of North American Tadpoles. Archives of Environmental Contamination and Toxicology, 48, 351357.

Santadino M, Coviella C \& Momo F 2014, 'Glyphosate sublethal effects on the population dynamics of the Earthworm Eisenia fetida (Savigny, 1826)', Water Air Soil Pollution, 225, 2207.

Sari, YK, Niswati, A, Arif, MAS \& Yusnaini S 2015, 'Pengaruh sistem olah tanah dan aplikasi herbisida terhadap populasi dan biomasa cacing tanah pada pertanaman ubi kayu (Manihot utilissima), J. Agrotek. Tropika, 3(3), 422-426.

Sartori F \& Vidrio E 2018, 'Environmental fate and ecotoxicology of paraquat: a California perspective', Toxicology \& Environmental Chemistry, 100, 479-517.

Scheu S 2003, 'Effects of earthworms on plant growth: patterns and perspectives', Pedobiologia, 47, 846-856.

Tilman D, Cassman KG, Matson PA, Naylor R \& Polasky S 2002, 'Agricultural sustainability and intensive production practices', Nature, 418, 671-677.

Van Groenigen JW, Lubbers IM, Vos HMJ, Brown GG, De Deyn GB \& van Groenigen KJ 2014, 'Earthworms increase plant production: a meta-analysis', Scientific Reports, 4, 6365.

Verrel P \& van Buskirk E 2004, 'As the worm turns: Eisenia fetida avoids soil contaminated by a glyphosate-based herbicide', Bulletin of Environmental Contamination and Toxicology, 72, 219-224.

Walker A, Cotterill EG \& Welch SJ 1989, 'Adsorption and degradation of chlorsulfuron and metsulfuron-methyl in soils from different depths', Weed Research, 29(4), 281-287.

Woodburn AT 2000, 'Glyphosate: production, pricing and use worldwide', Pest Management Science, 56, 309-312.

Yasmin S \& D'Souza D, 'Effects of pesticides on the growth and reproduction of earthworm: A review', Applied and Environmental Soil Science, 2010, 678360.

Zaller JG, Heigl F, Ruess L, Grabmaier A 2014, Glyphosate herbicide affects belowground interactions between earthworms and symbiotic mycorrhizal fungi in a model ecosystem. Scientific Reports, 4, 5634.

Zhou C, Wang YJ, Li CC, Sun RJ, Yu YC \& Zhou DM 2013, 'Subacute toxicity of copper and glyphosate and their interaction to earthworm (Eisenia fetida)', Environmental Pollution, 180, 71-77. 